\title{
Alfa - 1 - antitripsina fecal en la lactante. Valores de referencia y en el síndrome diarreico agudo
}

\author{
Dr. Gastón Duffau T.; Dr. Agustín León C.; T.M. Pedro Farjas T.; \\ Dr. Gonzalo Urcelay M. \\ Fecal alpha-1-antitrypsin in infants. \\ Reference values and in acute diarthoeal disease
}

\begin{abstract}
Alpha-1-antitrypsin (a-1-AT) was determined in faeces by agorose radial inmunodiffusion plates in order to establish reference values in random faecal samples, and to determine the magnitude of intestinal protein loss in acute diarshoea and its eventual association with the aetiology and clinical progress of the disturbance. Fifty three patients 1 to 11 months of age were studied. Fifteen infants admitied with acute respiratory disease, were investigated when fully recovered, just before discharge: reference values found were (ng/g dry weight): 4.80 to $50.80\left(x \pm 2 \mathrm{SD}_{n-1}\right)$. Thirty eight cases with acute diarthoea were studied within 24 hours after admission: increased faecal a-1-AT loss was detected in $\mathbf{4 7 , 3 \%}$ of these patients, with 3 cases showing loses greater than 100 mgfy. Severe malnutrition was not obseryed. Faccal I*1-AT loss was neither related to nutritional status nor to the aetiology of diarrhoea. However, increascd loss was associated to watery stools, prolonged hospitalization and probably to protracted diarrhoea $(p=0.05)$.

(Key words: alpha-1-antritrypsin, infants, acute diartioea, reference values).
\end{abstract}

La pérdida enteral de proteínas plasmáticas es un factor reconocido en la tendencia a la hipoalbuminemia y desnutrición de una diversidad de trastornos gastrointestinales ${ }^{1-5}$. Cabe señalar sin embargo, que hay poca información referente a este fenómeno en el síndrome diarreico agudo del lactante 6,7 .

En la cuantificación de proteinas séricas trans. feridas al lumen enteral, la determinación de la concentración fecal de alfa-1- antitripsina ha demostrado ser un método confiable, con la ventaja de ser una técnica simple y no invasiva, en comparación con procedimientos usados previamente ${ }^{3,4,8}$.

En la literatura nacional a nuestro alcance, no hemos encontrado estudios sobre este problema aunque el síndrome diarreico agudo es una importante causa de morbilidad y deterioro

1. Departamento de Pcdiatría, División Cicncias Médicas Norte, Facultad de Medicina, Universidad de Chile, Roberto Roberto del Río. Financiado parcialmente por Grant N.N.R.G.P. 82/35. nutricional en lactantes de nuestro mediog-11. Por ello nos ha parecido necesario, en primer término, establecer valores de referencia de concentración fecal de alfa-1-antitripsina y luego, verificar si el paso excesivo de seroproteinas a través de la pared intestinal y ulterior pérdida es de relevancia en esta patología, intentando precisar con que frecuencia se da el fenómeno, su relación con la etiología de la diarrea y su ingerencia en el tipo de evolución, hipotetizando que la eliminación elevada de proteínas plasmáticas en las heces es un factor de riesgo de evolución prolongada.

\section{MATERIAL Y METODO}

Sc estudiaron dos grupos de niños de 1 a 11 meses de edad, hospitalizados en la Unidad de Lactantes del Hospital Rober to del Río: Quince pacientes que proporcionarían los valores de referencia de alfa-1-antitripsina fecal, internados por enfermedades respiratorias, sin trastorno digestivo clínicamente pesquisable, en los que se obtuvo una muestra de deposición una vez asintomáticos, antes del alta y treinta $y$ ocho nifios con síndrome diarreico agudo, en los que se obtuvo una muestra de deposición dentro de las primeras $2 \mathbf{A}$ horas de hospitalización. 
La determinación de alfa-1-antitripsina se realizó de acuerdo al método de Crossley \& Elliot ${ }^{3}$, usando placas de inmunodifusión radial dotadas de pocillos en agarosa impregnada con suero alfa-1-antitripsina humana. Las muestras recogidas fueron conservadas hasta la determinación a $4^{\circ} \mathrm{C}$, sin preservar alguno. Homogenizada la muestra de deposición, se tomó una alícuota para establecer su peso seco mediante método de calentamiento hasta peso constante. Un gramo de deposjción homogenizada, pesado en una balarza eléctrica con un grado de precisjón que alcanzó al décimo de miligramo, fue diluído en agua destilada hasta un volumen aforado de $10 \mathrm{ml}$ Esta solución se centrifugó a $3.000 \mathrm{rpm}$. durante 30 minutos y del sobrenadante se depositaron $5 \mu$ en los pocillos de agar. Después de $\mathbf{4 8}$ horas de incubación a temperatura ambiente, se midieron los halos de precipitación y se compararon con la curva patrón del método. Los resultados de concentración fecal de alfa-1-antitripsina se expresaron en $\mathrm{mg} / \mathrm{g}$ de peso seco de deposición.

En todos los casos se realizó una investigación etiológica que incluyó: salmonella, shiguetla, parásitos intestinales $y$ rotavirus, este úlimo mediante la electro. foresis del ácido nucleico viral ${ }^{12}$.

En cada nin̄o se consignó la información pertinente en un formulario especial que incluyó: datos de identificación, edad, sexo, estado nutricional evaluado según criterio de relación peso/talla ${ }^{13}$, diagnósticos de ingreso $y$ egreso, duración anamnéstica e intrahospitalaria de la diarrea, características y porcentaje de humedad de las deposiciones, etiología encontrada del sindrome diarreico, duración de la hospitalización, intercurrencias $y$, finalmente, concentración de alfa-1-antitripsina en las heces.

Los resultados númericos se expresaron en términos de promedio, desviación estándar y error estándar del promedio, en el gupo de referencia. La relación entre algunas variables clínicas y pérdida de alfa-1-antitripsina fecal se determinó utilizando esencialmente la prueba de Fisher y arálisis de correlación 14.

El nivel de estor alla establecido para este trabajo fue menor que $5 \%(\mathrm{p}<0,05)$.

Este estudio corresponde a un proyecto aprobado por el Comité de Investigación y Extensión del Departamento de Pediatría.

\section{RESULTADOS}

El grupo que generará los valores de referencia de alfa.1.l antitripsina en heces, tuvo las siguientes caracteristicas: Siete casos fueron mayores de 6 meses y los restantes de 1 a 6 meses de edad al ingreso; la edad promedio fue de 5,1 meses. Once niños eran de sexo masculino y el estado nutricional del conjunto era normal en 7 , sobrepeso en $6 \mathrm{y}$ desnutrición leve en 2 pacientes. El diagnóstico de admisión fue bronconeumonia en $5 \mathrm{y}$ sindrome bronquial obstructivo en 4. Todos los ninos tenían deposiciones normales $y$ al tomar la muestra para estudio estaban asintomáti. $\cos \mathrm{y}$ en situación de egresar. Los valores encontrados de alfa-1-antitripsina, en $\mathrm{mg} / \mathrm{g}$ de peso seco de deposiciones, fueron: $\bar{x}=27,80$ oon $\mathrm{DE}_{\mathrm{n}-1} \pm 11,50$, lo que indicó como límites de discriminación, $\left(\bar{x} \pm 2 \mathrm{de}_{\mathrm{n}-1}\right)$, las cifras $4,80 \mathrm{y}$ 50,80 . No se encontró una correlación impor. tante entre edad y concentración fecal de alfa-1antitripsina, puesto que $\mathrm{r}=0,298(\mathrm{p}>0,05)$. Lo mismo se observó con el estado nutricional en el grupo $(r=0,151$ y $p>0,05)$.

Por otra parte los niños hospitalizados por sindrome diarreico, mostraron los siguientes rasgos básicos: siete niños eran mayores de 6 meses y los restantes 31 tenian de 1 a 6 meses de edad. Eran de sexo masculino 23 enfermos y el estado nut ricional del conjunto mostraba sobrepeso en 4. normalidad en 18 , desnutrición leve en $11 \mathrm{y}$ moderada en 4 lactantes. El diagnóstico de ingreso flie síndrome diarreico agudo en todos. En 18 ocasiones $(47,3 \%)$, se evidenció un rivel de pérdida de alfa-1-antitripsina por deposiciones superior al limite de referencia. La intensidad de la pérdida se puede mostrar serialando que en estos niños el margen fue de 53,12 a $149,43 \mathrm{mg} / \mathrm{s}$ de peso seco de deposiciones, con tres casos en el nivel de excreción sobre $100 \mathrm{mg} / \mathrm{g}$. Tampoco en este grupo se encontró una correlación importante entre edad y concentración fecal de alfa-1-antjtripsina ( $\mathrm{r}=0,304$ y $\mathrm{p}>0,05)$. La investigación etjológica resultó positiva en 18 enfermos, mostrando rotavirus en $\mathbf{1 7}$ de ellos y quistes de giardia lamblia en el restante.

En la tabla es posible observar que el nivel de pérdida de alfa-1-antitripsina no se encuentra relacionado con el estado nutricional al ingreso o con la etiologia de la diarrea: al comparar los casos con hallazgo de rotavirus versus los restantes pacientes. Asimismo, se puede precisar que la presencia de deposiciones liquidas o semiliquidas se encuentra asociada a una excreción mayor de alfa-1-antitripsina. La duración de la diarrea es mayor entre aquellos con pérdida proteica más elevada, aunque en "p" límite. Sin embargo, en éstos la hospitalización tiene clara tendencia a ser más dilatada. Es interesante indicar que, si en el grupo con diarrea se excluyen los lactantes qué durante su internación presentaron algún episodio de intercurrencia digestiva, la duración de la hospitalización se hace comparable entre aquellos con excreción dentro del margen de referencia y los restantes. 
Tabla 1

Alfa-1-antitripsina en deposiciones $y$ algunas variabies clínicas en lactantes hospitalizados por sindrome diarreico agudo.

\begin{tabular}{|c|c|c|c|}
\hline & \multicolumn{3}{|c|}{$\begin{array}{l}\text { Soncentración fecha de } \\
\text { alfa-l-1antitcipsina } \\
\text { Ln matgen } \\
\text { de Ee Elevada } \\
\text { referencia }\end{array}$} \\
\hline & \multicolumn{2}{|c|}{$\left(1 \mathrm{a}=38 \mathrm{r}^{\prime \prime}\right.$} & po \\
\hline \multicolumn{4}{|c|}{ l:stado nutyicjonal *** } \\
\hline \multicolumn{4}{|c|}{ A] ingrese } \\
\hline $\begin{array}{l}\text { NoSP } \\
D_{1} \Leftrightarrow D_{2}\end{array}$ & 12 & 11 & 0,30 \\
\hline \multicolumn{4}{|c|}{ litioloyia de la diartea: } \\
\hline Rotavisus & 10 & 7 & 0.20 \\
\hline Otra & 10 & 11 & 0.20 \\
\hline \multicolumn{4}{|c|}{ (arjeter de lis heces ${ }^{* * x}$} \\
\hline D & 11 & 1 & 0.0011 \\
\hline SL.L & 9 & 17 & 0.0011 \\
\hline \multicolumn{4}{|c|}{ Duracjón de lis tiarrea. } \\
\hline$\Leftrightarrow 10$ dias & 15 & 8 & \\
\hline$>10 \mathrm{dids}$ & 5 & 10 & $0,0) 25$ \\
\hline \multicolumn{4}{|c|}{ Duraciun de la los jutalizacion } \\
\hline$>14$ dias & $\begin{array}{r}14 \\
6\end{array}$ & 12 & 0.025 \\
\hline \multicolumn{4}{|c|}{ 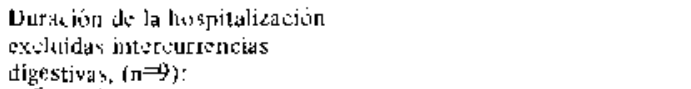 } \\
\hline$\leqslant\left|4 i i_{i}\right| s$ & 12 & 5 & \\
\hline$>14$ dias & 5 & $?$ & 0,12 \\
\hline
\end{tabular}

* Jixceplue en último rubro, en gut $\pi=29$.

* Catakegado sceun criterio pesoitalla. con niño hidratudo $\checkmark, S \Gamma, D_{1} \cdot D_{2}=$ nurmis primer y segundo grado, respectiyamente.

*** D. \$I., L.: djsgresado, semiliquad o y líquids

a Por pruclas de listicr, de prubabilidades exactas.

\section{COMENTARIO}

Alfa-l-antitripsina es una proteina presente en el plasma, sintetizada en el higado, intibidora de proteasa, resistente a la proteolisis y consecuentemente no degradada por la enzimas pancreáticas, lo que la hace detectable en forma inalterada en las heces ${ }^{3,8,15,16}$. Por otra parte, esta antienzinna no se encuentra en la alimentación y es una glicoproteína de peso molecular similar al de la albúmina, por to que se admite que encontrarla en concentración aumentada en las deposiciones necesariamente traduce una permeabilidad elevada para las proteínas plasmáticas, fundamentalmente albúmina, hacia el lumen en. tera! ${ }^{8,17}$.

En este estudjo se cumplieron dos etapas muy claras, puesto que en primer término se estable. cieron valores de referencia de alfa-1-antitripsina en heces de lactantes, para anatizar posterormente la situación de niños del mismo grupo etario, hospitalizados por sindrome diarreico agudo. En el primer aspecto, cabe señalar que, empleando como marcador la mencionada proteina, se han sugerido diversas formas de medir y expresar la pérdida que afectan desde el proceso de homogenizacion-extracción hasta la forma de presentar los hallazgos, sea esto último en términos de depuración de alfa-1-antitripsina, concentración en $\mathrm{mg} / \mathrm{lo} \mathrm{mg} / \mathrm{g}$ de peso seco o como velocidad de excreción en $\mathrm{mg} / \mathrm{dí} a$ como relación de concentración heces/suero ${ }^{18}$. En este sentido los niveles de referencia encontrados por nosotros son claramente más alto que los publicados en otros medios ${ }^{4}$. Si bien la explicación de ello pudiera depender de alguna variante meto. dológica, no nos es evidente.

El hallazgo de pérdida exagerada de proteínas por las heces en $47,3 \%$ de los niños con diarrea, difiere substancialmente de lo encontrado por algunos en la misma afeccion y en diarrea crónica ${ }^{4}$, pero coincide con lo comunicado por otros $^{6}$.

La pérdida de proteína endógena contribuye a explicar el deterioro del estado nutricional que sufren los lactantes internados por sindrome diarrejco ${ }^{19}$. A este factor deben sumarse natural. mente otros, entre los cuales se ha visto sobresalir la anorexia 11 .

Es importante señalar que aún cuando una concentración alta de alfa-1-antitripzina en las deposiciones parece indicar la existencia de dafto en la mucosa, no establece su extensión o severidad ${ }^{4}$.

En la detección de pacientes con enteropatía perdedora de proteinas, la sensibilidad de alfa-1. antitripsina fecal es mayor que la proporcionada por la medición de albúmina sérica, por cuanto el higado puede inicialmente, compensar la pérdida de ésta última ${ }^{4}$.

Ni la edad o el estado nutricional, o aún la etiología de la diarrea, en los términos planteados mostró relacionarse con un patrón determinado de excreción de alfa-1-antitripsina. Cabe indicar que en otras series la variable etiología aparece determinante 7,19 . E1 carácter de las deposiciones 
indicó que las heces más líquidas se asociaban a mayor pérdida. Por otra parte, la duración de la hospitalización fue mayor en aquellos con eliminación elevada de la proteína y., en " $p$ " límite, ocurría algo similar con la duración del cuadro diarreico. Aparentemente, la más dilatada internación en aquellos con excreción alta de alfa-1. antitripsina en deposiciones se debería a que éstos se verfan afectados más frecuentemente por incurrencias de tipo digestivo.

\section{RESUMEN}

Se cuantificó alfa-1-antripsina (a-1-AT) en deposiciones, usando placas de inmunodifusión radial con agarosa, con el objeto de establecer valores de referencia en muestras aisladas de heces, precisar la frecuencia e intensidad de la pérdida proteica en el síndrome diarreico agudo, su relación con la etiologia y su influencia en la evolución clínica. Se estudiaron 53 niños de 1 a 11 meses de edad: En el Hospital Roberto del Río, quince niños ingresados por enfermedades respiratorias fueron investigados después de hacerse asintomáticos, antes del aita. Los valores de referencia encontrados fueron ( $\mathrm{mg} / \mathrm{g}$ de peso seco): 4,80 a $50,80\left(\bar{x} \pm 2 \mathrm{DE}_{\mathrm{n}-1}\right)$. Treinta $y$ ocho pacientes con síndrome diarreico agudo fueron estudiados en las 24 horas siguientes a la admisión: en $47,3 \%$ de ellos se detectó excreción elevada de a.1-AT, con 3 casos sobre $100 \mathrm{mg} / \mathrm{g}$. En ningún grupo hubo desnutridos severos. La pérdida aumentada de a-1-AT no se relacionó con el estado nutricional o la etiología de la diarrea, al comparar aquellos con rotavirus y los restantes, sin embargo se asoció a deposiciones líquidas o semilíquidas, hospitalización más dilatada y en valores límites de significación $(\mathrm{p}=0,05)$ a diarrea prolongada. La eliminación elevada de proteínas plasmáticas en lactantes hospitalizados por síndrome diarreico agudo es común y a veces severa, es esperable en cuadros con heces mis líquidas y a-1.AT sería un indicador de duración de la hospitalización y probablemente del tipo evolutivo del sindrome diarreico.

\section{REFERENCIAS}

1. Woldmann TA, Wochner R., Strober.: The role of the gastrointestinal tract in plasma protein metabolism. Am J Med 1969; 46: 275-285.

2. Waldmann TA.: Protein losing enteropa thy. Gastroenterology $1966 ; 50: 422-433$.

3. Crosstey J.R., Elliot R.B.: Simple method for diagnosing protein losing enteropathies. Br Med J 1977; 1: 428-429.

4. Thomas D.W., Sinatra F.R., Merrit R.J.: Random fecal alpha-l-antitrypsin concentration in children with gastrointestinal disease. Gastroenterology $1981 ; 80: 776-782$.

5. Beeken W.L., Buch H.S., Sylvester D.L.i Intestinal protein loss in Crohn's disease. Gastroenterology 1972; 62: 207-215.

6. Maki M., Harmoinen A., Vesikari T, Visakorpi J.K.: Fecal excretion of alpha-1-antitiypsin in acute diarrhoea, Arch Dis Child 1982; 57: 154:56.

7. Chen L.C., Scrimshaw N.S.:. Diarrhea and malnutrition, interactions. mechanism and interventions. New York: Plenum Press, 1983: 155-156.

8. Butler H.L., Isenberg J.N., Somerset J.S., Barnett D.R.: Quantitative fecal alpha-1-antitrypsin to measure gastrointestinal protein loss. Pediatr Res $1981 ; 15: 527$.

9. Duffau $G$,: Sindrome diarreico agudo del lactante. Santiago de Chile: Editorial Andrés Bello, 1978: 29-34.

10. Radrigan M.E.: Temas de nutrición y alimentación en pediatria. Santiago de Chile: Editorial Andrés, 1985: 59-96.

11. Duffou G., Faindez I.C., Osorio A.: Estado nutricional del lactante hospitalizado por patología respiratoria y digestiva. Estudio prospectivo. Bol Med Hosp Infant Mex 1986;43: 11-23.

12. Avendaño L.F, Ojeda J.M. Calderón M.A., et al: Detección de rotavirus en lactantes hospitalizados por diarrea. Rev Med Chil 1980; 108; 210-214

13. Aguiló C., Emparanza E., Rizzardini M.: Normas de atención pediátrica. Santiago de Chile: Editorial Andrés Bello, 1984: 1-17.

14. Siegel S.: Nonparametric statistics. New York: Mc Graw-Hill Book Co., 1956: 96-103.

15. Hitl R.E., Herez A., Corey M.L., et al: Fecal clearance of alpha-1-antitrypsin: a reliable measure of enteric protein loss in children. J Pediatr 1981; 99: 416-418

16. Shorp H.L.: The current status of alpha-1-antitrypsin, a protease inhibitor, in gastrointestinal disease. Gastroenterology 1976; 70: 611621.

17. Crawford I.P.: Purification and properties of normal human alpha-1-antitrypsin. Arch Bjochem Biophys $1973 ; 215-222$.

18. Keaney N.P. Kelleher J.: Fecal excretion of alpha-l-antitrypsin in protein losing enteropathy. Lancet 1980; 1:711.

19. Bellanti J.A.: Acute diarrhoea: its nutritional consecuences in children. Nestlé nutrition workshop series $N^{\circ} 2$, Vevey/New York: Raven Ptess, 1983: $89-90$. 